\title{
BIOGENIC POTENTIAL OF STABILIZED SILVER NANOPARTICLES USING G. SYLVESTRAE AND THEIR BIOLOGICAL ASSAYS
}

\author{
RAJESWARI ANBURAJ ${ }^{1 *}$, VINOTH JOTHIPRAKASAM ${ }^{2}$
}

${ }^{1}$ Department of Microbiology, M. I.E. T Arts and Science College, Trichy, ${ }^{2}$ CAS in Marine Biology, Annamalai University, Parangipettai-608 502, Tamil Nadu, India

Email: raji.anburaj@gmail.com

Received: 31 Oct 2018, Revised and Accepted: 30 Jan 2019

\section{ABSTRACT}

Objective: The idea of green chemistry has gained immense fame due to replace chemical products and improves technologies to eradicate substances that are harmful to the environment. In this paper, a rapid cost-efficient method was employed using herbal extract Gymnema sylvestrae because of their biological constituents present in the sample.

Methods: Phytosynthesis of AgNPs were optimized under different reaction conditions using $\mathrm{pH}$, temperature, incubated at various concentrations. Analyses of particles were revealed using UV-Vis, FTIR spectrum, morphology was observed in scanning electron microscope, particle analysis was done using Diffraction Light Scattering and bioactive constituents present in plant sample was analysed by High-performance liquid chromatography. Bioefficacy of synthesised AgNPs was assessed by means of microbicidal assay against various bacteria and fungi.

Results: UV and FTIR analysis reveals the presence of plant extract responsible for stabilization and efficient reduction. Peptides to proteins, polyphenols, and many other secondary metabolites involved in the bioreduction were identified. SEM micrograph reveals the nature, size and distribution of the sample. HPLC chromatogram indicated the presence of gymnemagenin responsible for their biological assays. Broad spectrum of microbicidal activity have been reported in $400 \mu \mathrm{l}$ of biosynthesized AgNPs against Bacillus sp. (24.5 mm), and S. epidermis (22.3 mm).

Conclusion: Therefore G. sylvestrae synthesized silver nanoparticles were stable and acts as a reducing and capping agent detecting the presence of biomolecules. Biosynthesised AgNPs showing excellent antimicrobial activity and future prospects of this study indicates that these nanoparticles can be applied in drug delivery.

Keywords: Bioreduction, Biofunctionalized, Optimization, Gymnemagenin

(C) 2019 The Authors. Published by Innovare Academic Sciences Pvt Ltd. This is an open access article under the CC BY license (http://creativecommons.org/licenses/by/4.0/) DOI: http://dx.doi.org/10.22159/ijap.2019v11i3.29227

\section{INTRODUCTION}

Bio functionalized materials in nanotechnology are employed for the synthesis of their required size, shape, and dispersivity properties [1]. In the present scenario the development of hygienic and green technologies for the nano synthesis, plays a vital role [2]. As a substitute to the physical method, green synthesis method employing plant extracts are proved to be more viable and simple. Synthesis of novel metal nanoparticles is a striking opportunity by using reducible bio-excretory and different plant extracts. Nanoparticles (NPs) can be developed using different plant extracts, microbial strains [3], enzymes, metabolites, biodegradable products [4], fungi, mushrooms and AgNPs are being investigated for application in biomedicine and to be used as bactericide agent or for cancer treatment [5]. Plant materials, including leaf [6], bark [7], fruit [8], peel [9], seed [10], and root [11] extracts work so well in the green synthesis of AgNPs under mild experimental conditions and replacing hazardous chemicals by polyphenols, flavonoids, proteins, saponins or sugar as reducing agents as well as capping agents. Metal nanoparticles have potential applicability in a variety of areas such as electronics, textile, catalysis, energy and medicine [12], antimicrobial [13, 14], antitumor effect [15], sensitivity to detect the presence of various pollutants such as metals and dyes $[16,17]$, antibiotics. Therefore, the progress of environmentally conscious, energy-efficient, facile, and rapid green synthesis that evade toxic chemicals has concerned significant attention [18].

Gymnema sylvestre $\mathrm{R}$. Br. belongs to the family Asclepiadaceae, is used as an efficient anti-diabetic medicinal herb. Leaves are rich in biological compounds like alkaloids, betaine choline, tartaric acid, triterpene saponins, gymnemic acid, anthraquinone derivatives and trimethylamine [19]. Anti sweet constituent of the leaves has been developed by the mixture of triterpene saponins. Chewing of leaves reduces sensitivity to sweet substances [20]. Glycosides isolated from plant have anaesthetic and topical effect resulting from the competition of the receptor sites between glycosides and the sweet substances [21].
Bioactive constituents of the plant include the gymnemic acids, saponins, stigmasterol, quercitol, and the amino acid derivatives betaine, choline, and trimethylamine. The saponin gymnemic acid, constituent of the leaves, was shown to suppress sweet taste sensation and to inhibit glucose absorption in the small intestine [22].

The aim of the present work was to apply the accurate principles of green methods for the development of biologically synthesised metal nanoparticles by using leaf extracts of $G$. sylvestrae. This method of synthesis with plant extract is advantageous because it is simple, highly reproducible, nontoxicity and can be processed at the room temperature. Microbicidal assessment of this phytosynthesised nanoparticles against pathogens indicate that this nanoparticle can be further used for the applications of drug delivery.

\section{MATERIALS AND METHODS}

Experimental section

\section{Chemicals and reagents used}

Silver Nitrate $\left(\mathrm{AgNO}_{3}\right)$ and solvents like acetone, chloroform, petroleum ether, ethanol, methanol, nutrient agar and potato dextrose agar were purchased from Sigma Aldrich, USA. All other reagents, chemicals and solutions used were of analytical grade.

\section{Preparation of plant material}

Gymnema sylvestrae was collected from local surroundings of Madurai of $9.9252^{\circ} \mathrm{N}$ latitude and $78.1198^{\circ} \mathrm{E}$ longitude region. Fresh leaves were used for the extraction of active components were shade dried at room temperature and powdered using electrical blender. These powdered samples were stored in an airtight container.

\section{Qualitative phytochemical examination}

The dried plant material was successively extracted with acetone, chloroform, petroleum ether, ethanol, methanol and kept in shaker for $2 \mathrm{~d}$. The solvent was evaporated using rotary evaporator under 
reduced pressure at $37{ }^{\circ} \mathrm{C}$. The plant extract was subjected to phytochemical analysis by the method described by Harborne [23]. The extract was screened for the presence of bioactive compounds like alkaloid, flavonoid, glycosides, phenol, saponin, steroid, tannin and terpenoids.

\section{Biosynthesis of silver nanoparticles}

Aqueous solution $(1 \mathrm{mmol})$ of silver nitrate $\left(\mathrm{AgNO}_{3}\right)$ was prepared and used for the synthesis of AgNPs. $5 \mathrm{ml}$ of $G$. sylvestrae along with $95 \mathrm{ml}$ of aqueous solution of $1 \mathrm{mmol} \mathrm{AgNO}_{3}$ was mixed for reduction into Ag+ions. In a typical synthesis of silver $(\mathrm{Ag})$ nanoparticles the leaf extract $(1.5 \mathrm{ml})$ was added to $30 \mathrm{ml}$ of $10^{-3} \mathrm{M} \mathrm{AgNO}_{3}$ aqueous solution in a $250-\mathrm{ml}$ Erlenmeyer flask and heated on water bath at $75{ }^{\circ} \mathrm{C}$ for 60 min. Bioreduction of $\mathrm{Ag}$ ions was observed by means of brownish colour further experimented using spectrophotometric determination. The product was redispersed in deionized water and the centrifugation was continued constantly for two to three times to remove the absorbed substances on the surface of nanoparticles [24].

\section{Microorganisms}

Bacteria such as Escherichia coli, Bacillus cereus, Klebsiella pneumonia, Klebsiella terrigena, Pseudomonas aeruoginosa, Staphylococcus aureus, and Staphylococcus epidermis. Fungal organisms such as Fusarium oxysporum, Penicillium and Aspergillus niger were obtained from GH hospital, Madurai. The bacterial cultures were maintained on nutrient agar slants at $4{ }^{\circ} \mathrm{C}$ and the fungal cultures were maintained on potato dextrose broth at $25^{\circ} \mathrm{C}$.

\section{Preparation of inoculum}

The bacterial cultures were inoculated into the nutrient broth and incubated for $24 \mathrm{~h}$ at $37{ }^{\circ} \mathrm{C}$. The growth was compared with 0.5 McFarland; the turbidity of the medium indicates the growth of organisms, while the fungal cultures were inoculated into potato

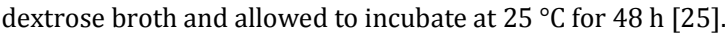

\section{Antimicrobial assay of silver nanoparticles}

The AgNPs synthesized from Gymnema sylvestrae were tested for antimicrobial activity by well-diffusion method against pathogenic microbes. Standard agar well diffusion method was employed to detect the assay of AgNPs against the microbial isolate according to Cheesbrough [26]. For microbicidal assay of the compounds, wells were made in plates containing nutrient agar medium seeded with $100 \mu \mathrm{l}$ of $24 \mathrm{~h}$ of each microbial isolate. The wells were loaded with G. sylvestrae, $\mathrm{AgNO}_{3}$ and plant-based synthesized silver nanoparticle was loaded using a micropipette. From each solution, that contains both Ag and G. sylvestrae extracts, as well as the control, synthesized silver nitrate was placed in separate wells. $\operatorname{Agno}_{3}(200 \mu \mathrm{l})$ solution was used as a standard to determine their inhibition potential. The plates were left in the refrigerator for $2 \mathrm{~h}$ then incubated at $37^{\circ} \mathrm{C}$ for $24 \mathrm{~h}$. The diameter of the inhibition zones was calculated and tabulated by comparing with standard.

\section{UV-Vis spectroscopy}

The synthesized AgNP were observed visually for any colour change and one $\mathrm{ml}$ of the reaction mixture were withdrawn consecutively at various time levels by diluting a small aliquot $(100 \mu \mathrm{l})$ of the sample 10 -fold in deionized water for analysis of surface plasmon resonance of silver nanoparticles. The reduction of pure Ag+ions was monitored by measuring using a UV-Vis spectrophotometer (Shimadzu 1601 model, Japan) at the resolution of $1 \mathrm{~nm}$ in the range of 200-800 nm.

\section{FT-IR analysis}

The functional groups of the nanoparticles were qualitatively confirmed by using FTIR spectroscopy, with spectra recorded by a Perkin-Elmer Spectrum 2000 FTIR spectrophotometer. Approximately $3 \mathrm{mg}$ of lyophilized sample along with $300 \mathrm{mg}$ of dried $\mathrm{KBr}$, was mixed and crushed well in mortar and pestle to prepare thin pellet for analysis. Scans per sample were performed in range of $400-4000 \mathrm{~cm}^{-1}$ [27].

\section{Scanning electron microscopy (SEM)}

The structure and composition of freeze-dried purified silver particles were analyzed by using a $10-\mathrm{kV}$ ultra-high resolution scanning electron microscope. A drop of aqueous solution containing purified silver nanomaterials obtained after repetitive centrifugation was sputter coated on carbon-coated copper grids and the images of nanoparticles were studied using FEI QUANTA-200 SEM.

\section{Particle size analysis and Zeta potential}

Particle size analysis of silver nanoparticles was analysed on particle size analyzer system (Zeta sizer, Malvern Instruments Ltd., USA).

\section{RESULTS AND DISCUSSION}

\section{Authentication of plant material}

Fresh leaves of G. sylvestrae were authenticated by Dr. S. John Britto, The Director, The Rapinat herbarium and center for molecular systematic, St. Joseph's College, Tiruchirapalli, Tamilnadu. Voucher specimens of the dried drugs were deposited in the herbarium of the centre for molecular systematic, St. Joseph College, the obtained voucher number is AR 001/21/12/18.

Table 1: Phytoconstituents present in G. sylvestrae

\begin{tabular}{|c|c|c|c|c|c|}
\hline Phytoconstituents & Hexane & Chloroform & Ethyl acetate & Methanol & Water \\
\hline Alkaloid & - & + & + & + & + \\
\hline Flavanoid & - & - & + & + & + \\
\hline Saponin & - & - & - & + & + \\
\hline Tannin & + & - & - & + & - \\
\hline Phenol & + & + & + & + & - \\
\hline Glycosides & - & - & + & - & + \\
\hline Terpenoid & + & + & - & + & + \\
\hline Steroid & - & + & - & + & + \\
\hline
\end{tabular}

+: Present,-: absent. The results are replicates of samples.

\section{Phytochemical analysis of $G$. sylvestrae}

Investigations on the phytochemical screening of G. sylvestrae revealed the presence of biological compounds were represented in table 1. Methanol extract possess majority of the active constituents except glycosides, whereas in aqueous extract tannins and phenols were absent. The presence of phytoconstituents such as alkaloids, flavonoids, tannins, and phenolic compounds was responsible for several medicinal properties such as antioxidant, antimicrobial, antiinflammatory and anticancer activities etc. [28]. Ethyl acetate extract displayed positive result towards alkaloid, flavanoid, phenol and glycosides. In hexane and chloroform extract flavanoid, saponin and glycosides were absent, whereas indicates the presence of phenol and terpenoid. Whereas metabolites like plants containing different proteins and secondary metabolites such as alkaloids, quinines, flavonoids, terpenoids and saponins $[29,30]$ are involved in the synthesis and stabilization of AgNPs.

\section{Phytosynthesis of AgNPs}

AgNPs are synthesized by means of plant extract mediated process, $\mathrm{AgNO}_{3}$ along with G. sylvestrae is incubated for several hours 
indicates the brownish colour. This can be attributed to the large amount of reductants (electron-rich phytomolecules) in the reaction medium, which cause the rapid reduction of $\mathrm{Ag}$ ions. The fast reduction of Ag ions usually facilitates that plant extract contain a variety of naturally occurring phytomolecules, such as water-soluble flavonoids, alkaloids, and several other phenolic compounds, which are broadly classified as polyphenols [31, 32]. These polyphenolbased phytomolecules acquire strong reducing properties and have a great tendency to adsorb on the surface of NPs [33].

\section{UV-Vis analysis of synthesized AgNP using G. sylvestrae}

Optimization parameters indicates the results of NPs synthesized were stable at $75^{\circ} \mathrm{C}$ temperature within $2 \mathrm{~h}$, at acidic (4) pH and basic (8.5) $\mathrm{pH}$, in the concentration of $2 \mathrm{mmol}$ is indicated in fig. 1-5. UV-visible spectroscopy is used for measuring the reduction of metal ions based on optical properties. Biological synthesis of AgNPs involves mixing the aqueous extract with an aqueous solution of $\mathrm{AgNO}_{3}$. The various biomolecules present in the plant extract such as enzymes, proteins, flavonoids, terpenoids and cofactors act as both reducing and capping agents [34]. Previous studies indicate that neutral $\mathrm{pH}$ is responsible for silver nanoparticle synthesis [35]. The biosynthesis can be performed in ambient conditions and by the standards prescribed in green chemistry. Reaction temperature and the dosage of the tea extract showed an effect on the production efficiency and formation rate of nanoparticles [36]. Chemical and physical methods are inconvenient as they are unstable and toxic, these conditions can be satisfactorily solved by biosynthetic processes. In this study, the aqueous extract of G. sylvestrae is used for the synthesis of Agnp. The synthesis of silver nanoparticles occurs at the room temperature in various periods and incubation time plays an important role in the formation of nanoparticles by reducing the silver ions at room temperature.

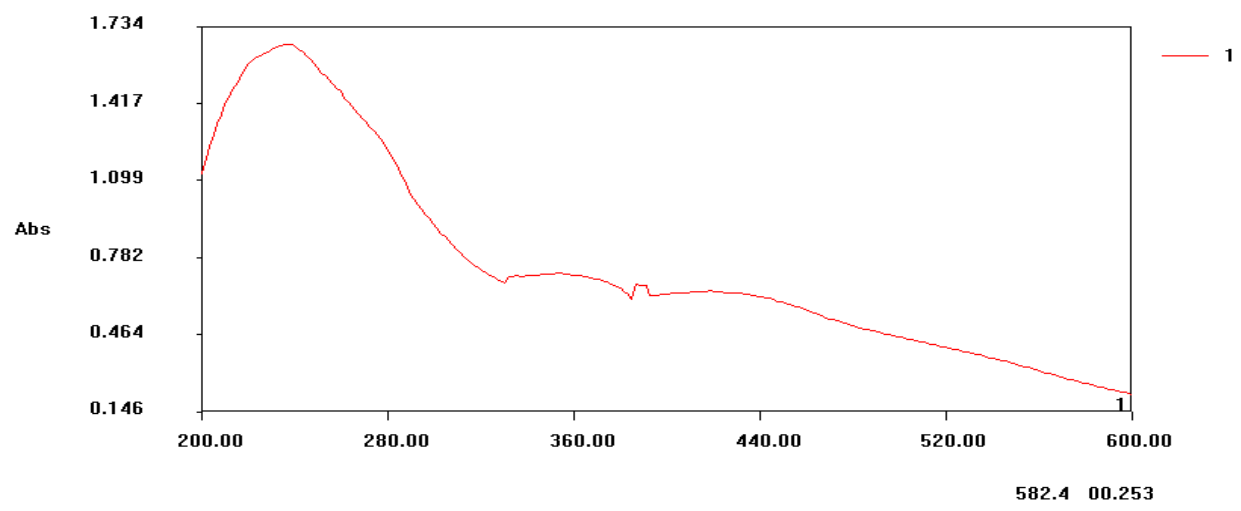

Fig. 1: UV-Vis analysis of synthesized AgNPs at $75^{\circ} \mathrm{C}$

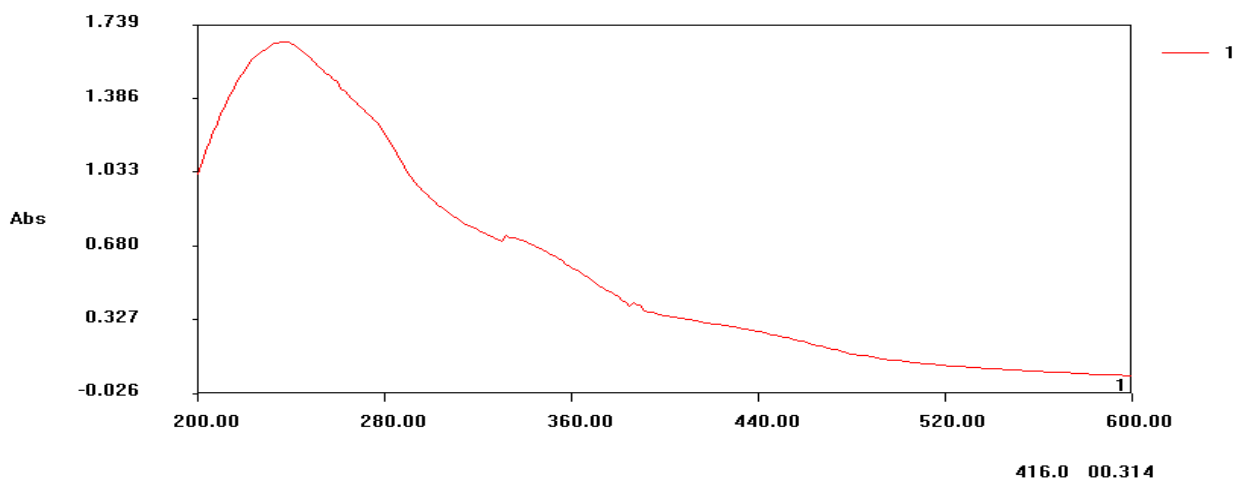

Fig. 2: UV-Vis analysis of synthesized AgNPs at $2 \mathrm{~h}$

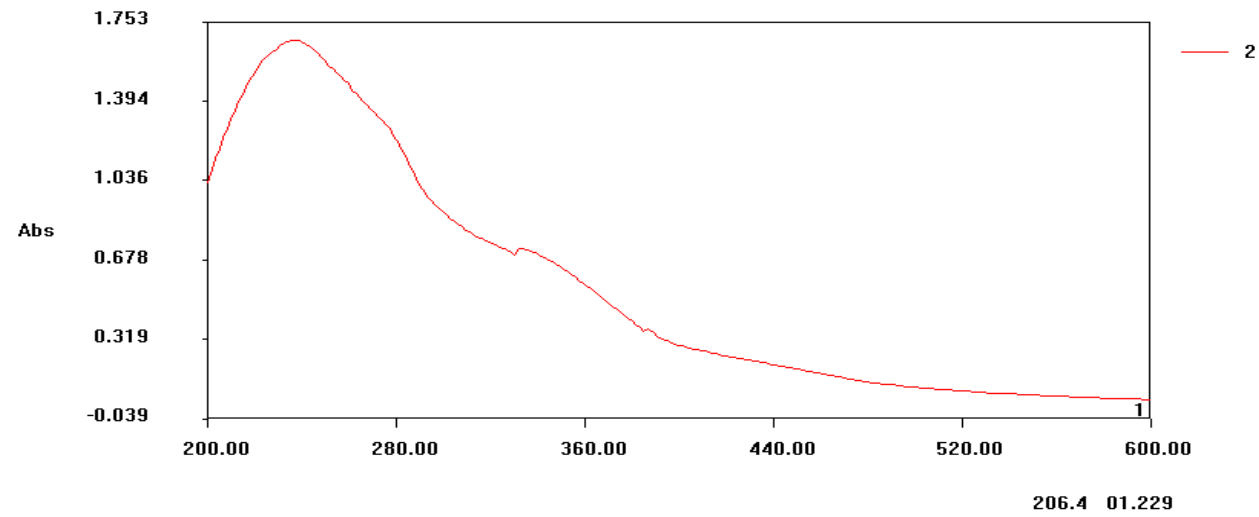

Fig. 3: UV-Vis analysis of synthesized AgNPs at pH 4.5 


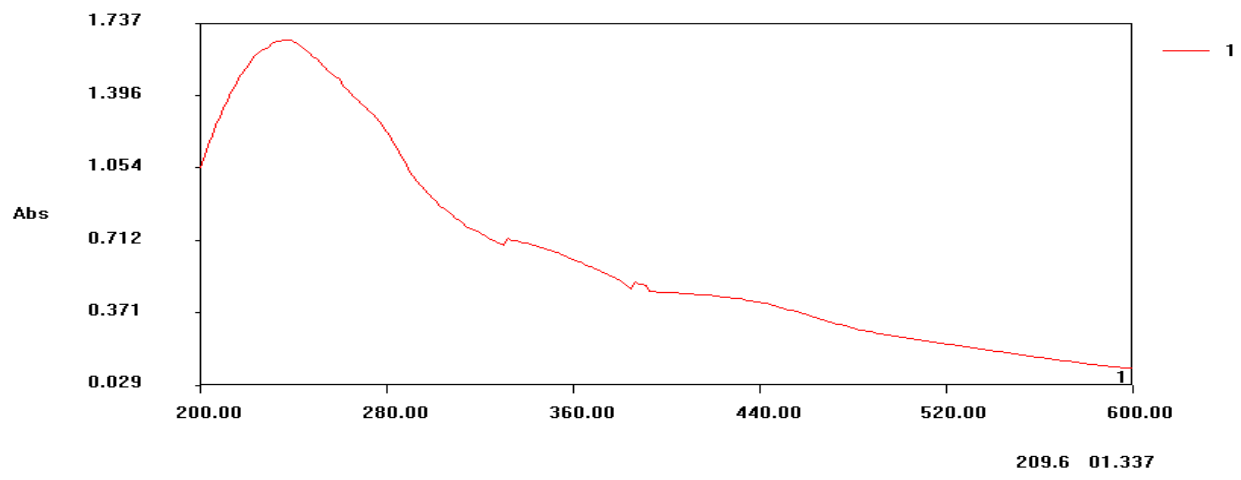

Fig. 4: UV-Vis analysis of synthesized AgNPs at pH 8.5

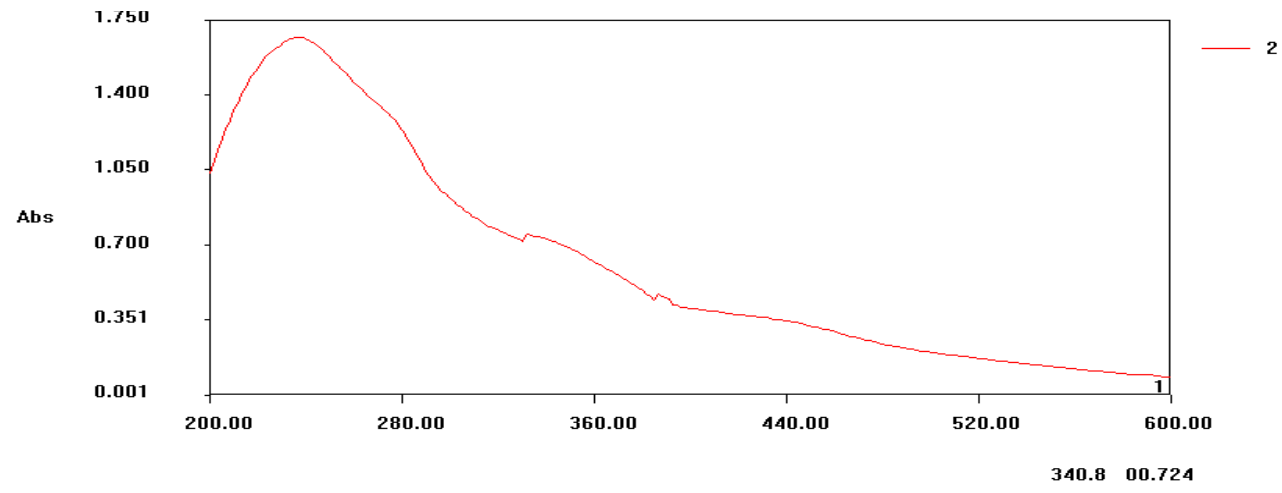

Fig. 5: UV-Vis analysis of synthesized AgNPs at $2 \mathrm{mmol}$

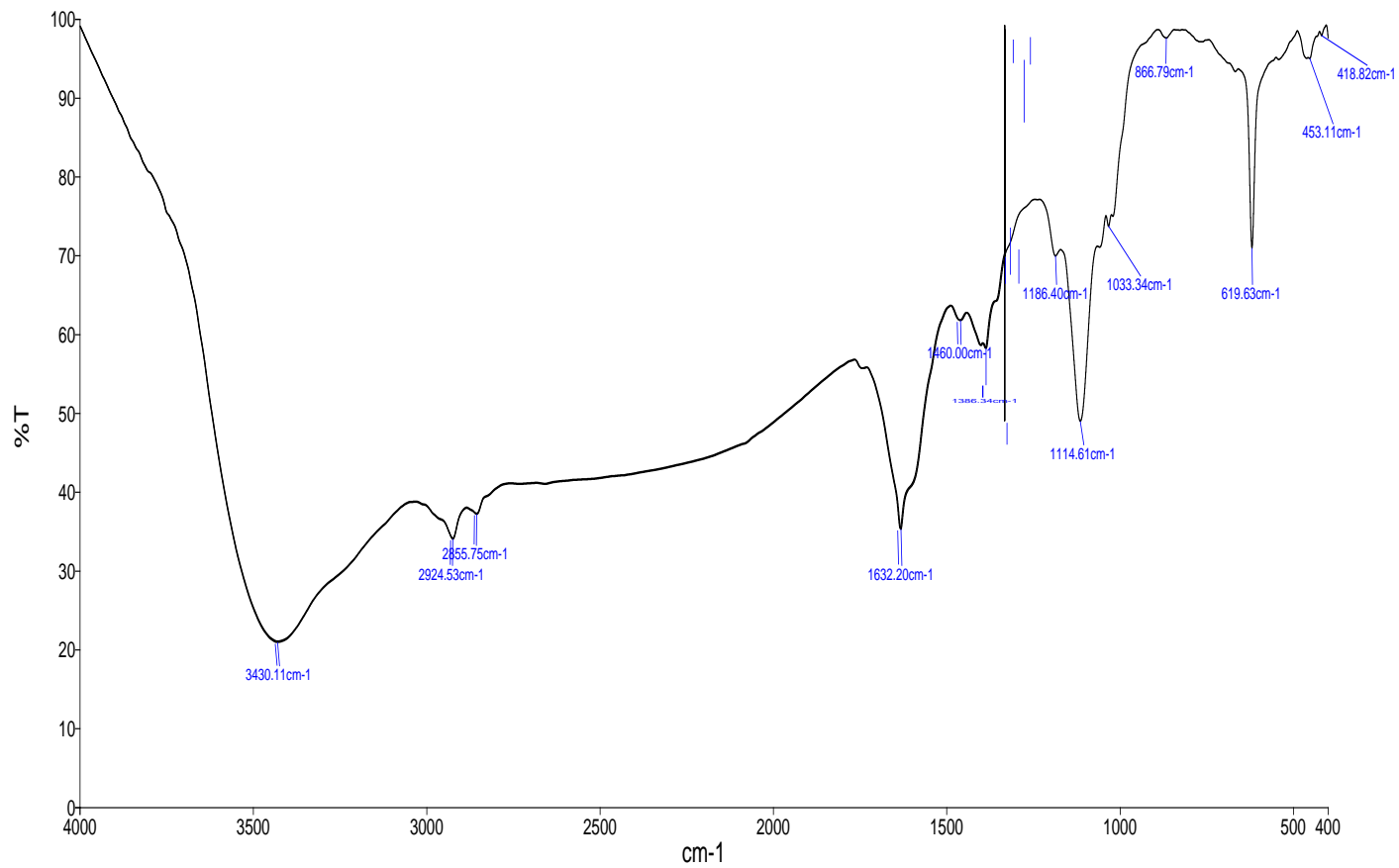

Fig. 6: FTIR spectrum of synthesized AgNP using G. sylvestare

\section{FTIR analysis of biosynthesized AgNPs}

FTIR spectrum of phytosynthesized AgNPs using G. sylvestrae were depicted in fig. 6 . The wavenumber at $3430 \mathrm{~cm}^{-1}$ corresponds to $\mathrm{N}-\mathrm{H}$ stretch of amino compound, followed by $2924 \mathrm{~cm}^{-1}, 2855 \mathrm{~cm}^{-1}$ belongs to methylene $\mathrm{C}-\mathrm{H}$ asymmetric/symmetric stretching of alkane group. The spectral results revealed that most of the bands were representative of flavonoids and terpenoids and vibrational bands corresponding to bonds such as $-\mathrm{C}=\mathrm{C},-\mathrm{C}-\mathrm{O}-\mathrm{C},-\mathrm{C}=\mathrm{O},-\mathrm{C}-\mathrm{O}$ and-C-N were derived from the plant metabolites like thiamine, flavonoids and terpenoids present in G. sylvestrae. This result suggests that plants are responsible for proficient stabilization of 
AgNPs [37, 38]. The functional group at $1632.20 \mathrm{~cm}^{-1}$ corresponds to primary amide $\mathrm{NH}_{2}$ bending, followed by $1460 \mathrm{~cm}^{-1}$ of $\mathrm{C}=\mathrm{C}$ stretching of aromatic compounds. Ziziphora tenuiora leaves functionalized with biomolecules that have primary amine group, carbonyl group, hydroxyl groups and other stabilizing functional groups as shown by FTIR spectroscopic technique [39]. The wavenumber at $1186.40 \mathrm{~cm}^{-1}, 1114.61 \mathrm{~cm}^{-1}, 1033.34 \mathrm{~cm}^{-1}$ belongs to $\mathrm{C}-\mathrm{O}$ stretching of alcohol and phenol group, followed by $866.79 \mathrm{~cm}^{-1}$ belongs to out of plane $\mathrm{C}-\mathrm{H}$ bending of aromatic compounds, $619 \mathrm{~cm}^{-1}$ of $\mathrm{C}-\mathrm{H}$ bend of alkyne group. This complex molecule becomes unstable and hydroxyl group reduces the silver ion $\left(\mathrm{Ag}^{+}\right)$to silver $(\mathrm{Ag} 0)$, thus producing stable AgNPs [40]. Previous study indicates that the carboxyl $(\mathrm{C}=0)$, amine $(\mathrm{N}-\mathrm{H})$, and hydroxyl- $\mathrm{OH}$ ) groups in carob leaf extract are chiefly involved in the reduction of silver ions. Previous results reveal that the protein present in leaf extract is incharge of stabilizing the AgNPs and thereby prevents agglomeration. Aminoacids along with carbonyl group signify the formation of a covering layer on AgNPs and thus acting as a capping agent to avoid agglomeration in the aqueous medium [41].

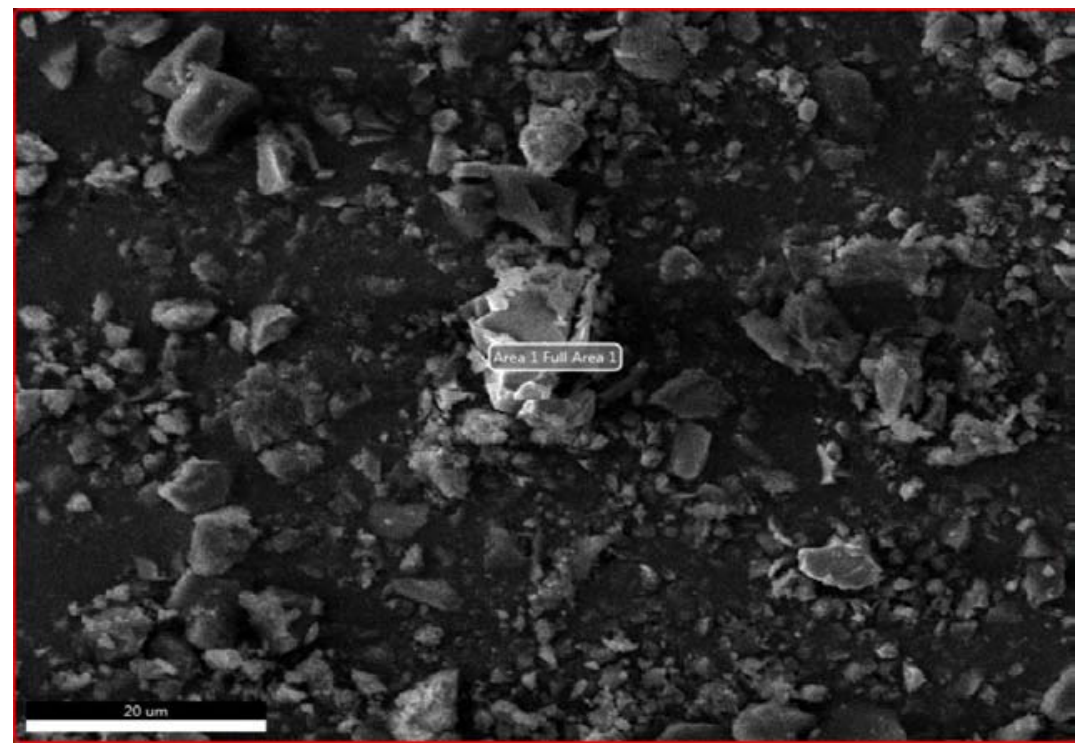

Fig. 7: Scanning electron micrograph of synthesized AgNPs using G. sylvestrae

\section{SEM result of biosynthesized AgNPs}

SEM images of AgNPs are depicted in fig. 7. Morphology and structure of biosynthesized AgNPs can be viewed by SEM. The results indicate that particles were sphere shaped and well distributed with aggregation. Organic molecules observed on surface particles can be viewed which serve as a reducing and also as a capping agent.

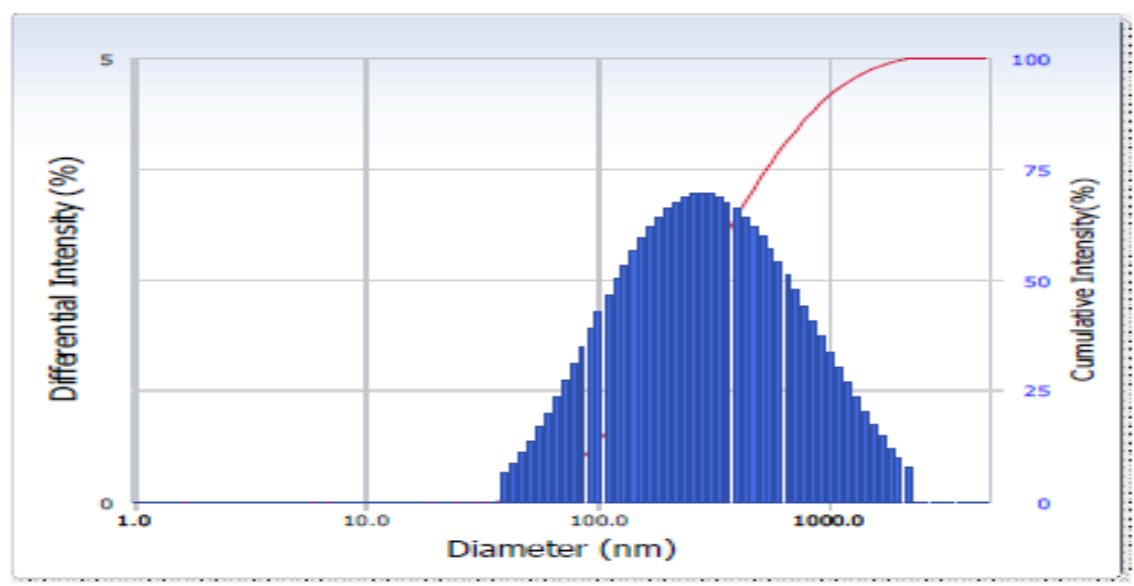

Fig. 8: DLS analysis of synthesized AgNP using G. sylvestrae

\section{DLS analysis of $G$. sylvestrae}

DLS analysis of plant-based AgNPs using G. sylvestrae were represented in fig. 8. The particle size distribution spectra for the silver nanoparticles were recorded as diameter (nm) on $\mathrm{X}$ axis verses frequency $(\% / \mathrm{nm})$ on $\mathrm{Y}$ axis. The results indicate that the nanoparticles were found to be well dispersed. Dynamic light scattering technique has been used to measure hydrodynamic diameter of the hydrosol (particle suspension). The size obtained by the DLS is different because it gives the average size of the particles. Gymnema sylvestre AgNPs was found to be $100 \mathrm{~nm}$.

The particle size obtained from DLS is different, due to the variation in principles used for measurement [42]. 


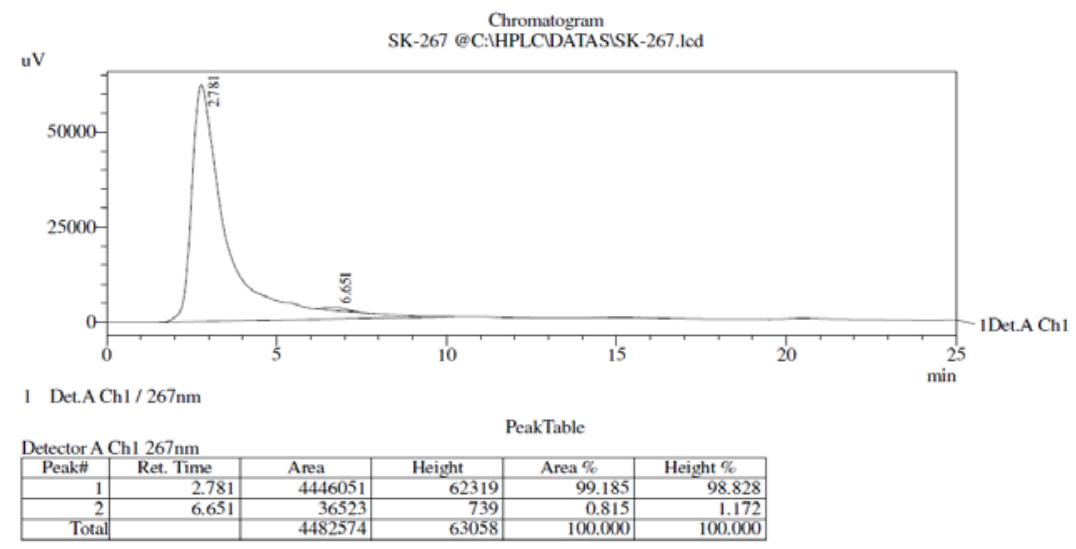

Fig. 9: HPLC analysis of Gymnema sylvestrae

\section{HPLC analysis of G. sylvestrae}

HPLC chromatogram of $G$. sylvestrae was represented in fig. 9. As HPLC is most widely used tool for quantification of analytes with good reproducibility an attempt has been made to develop a dependable and reproducible validated method for gymnemagenin estimation using HPLC. The retention time at 6.6 indicates the presence of gymnemagenin of $0.8 \%$. Gymnemagenin is a common genin of gymnemic acids which can be produced only after acidic and basic hydrolysis. The method reported in the literature [43] reports properly validated HPLC method for gymnemagenin estimation.

Table 2: Antimicrobial activity of G. sylvestrae

\begin{tabular}{llllll}
\hline S. No. & Microorganism & \multicolumn{2}{l}{ Gymnema sylvestrae } & & Ethyl acetate \\
\cline { 3 - 5 } & & Acetone & Chloroform & Ethanol & $22 \pm 0$ \\
\hline 1. & Bacillus cereus & $21.5 \pm 0$ & $19.3 \pm 0.2$ & $24 \pm 0.5$ & $17 \pm 0$ \\
2. & Klebsiella pneumonia & $16.3 \pm 0.2$ & $15.5 \pm 0$ & $19.5 \pm 0$ & $17.6 \pm 0.2$ \\
3. & Pseudomonas aeuroginosa & $18 \pm 0$ & $17.3 \pm 0.2$ & $20.4 \pm 0.1$ & $18.4 \pm 0.2$ \\
4. & Staphylococcus aureus & $20 \pm 0$ & $18.1 \pm 0.2$ & $22 \pm 0$ & $21.6 \pm 0.1$ \\
5. & Escherichia coli & $19.3 \pm 0.1$ & $18 \pm 0$ & $21.3 \pm 0.2$ & $19.5 \pm 0$ \\
6. & Mycobacterium mucliaginosus & $14.3 \pm 0.2$ & $14.3 \pm 0.2$ & $18.3 \pm 0.1$ & $15.1 \pm 0.2$ \\
7. & Klebsiella terrigena & $15.5 \pm 0$ & $15 \pm 0$ & $19.1 \pm 0.1$ & $16.5 \pm 0$ \\
8. & Fusarium oxysporum & $14.1 \pm 0.2$ & $12 \pm 0$ & $17.1 \pm 0.2$ & $16.5 \pm 0$ \\
9. & Penicillium & $16.5 \pm 0$ & $15.2 \pm 0.1$ & $19 \pm 0$ & $18.6 \pm 0.1$ \\
10. & Aspergillus niger & $15.3 \pm 0.1$ & $14.5 \pm 0$ & $18.3 \pm 0.2$ & $15.1 \pm 0.2$ \\
\hline
\end{tabular}

${ }^{*}$ values are mean of $\pm \mathrm{SD}, \mathrm{n}=3$

\section{Microbicidal assay of $G$. sylvestrae}

Bactericidal and fungicidal assay of $G$. sylvestrae were depicted in table 2. Maximum inhibitory effect was observed in ethanol extract against $B$. cereus $(24 \mathrm{~mm})$, ethylacetate $(22 \mathrm{~mm})$ and acetone extract (21.5 $\mathrm{mm})$, followed by $S$. aureus in ethanol $(22 \mathrm{~mm})$, ethyl acetate $(21.6 \mathrm{~mm})$ and acetone $(20 \mathrm{~mm})$. A glycoprotein isolated from $G$. sylvestrae exhibits good antibacterial activity against methicillinresistant Staphylococci and multi-resistant Enterococci 44. Moderate inhibitory effect was observed in $P$. aeuroginosa in ethanol $(20.4 \mathrm{~mm})$ and ethyl acetate $(18.4 \mathrm{~mm})$ followed by $K$. pneumonia (19.5 mm, $17.5 \mathrm{~mm})$, whereas least inhibition was observed in $M$. mucilaginosus in chloroform $(14.3 \mathrm{~mm})$ and petroleum ether $(13.3 \mathrm{~mm})$. Stronger extraction capacity of ethanol has yielded a number of active constituents responsible for antimicrobial effect
[45]. The results suggest that chloroform and petroleum ether extract remained sensitive towards the organism. Results corroborated with former reports suggests that the ethanolic extract of $G$. sylvestrae leaves possess superior antimicrobial activity against Bacillus subtilis, Pseudomonas aeruginosa, Staphylococcus aureus [46]. The experimented activity may be due to the occurrence of potent phytoconstituents in the extracts, the results correlate with previous reports [47]. The chief compounds of $G$. sylvestre includes gymnemic acid, saponins and oleanane-type of triterpenoid. Maximum fungicidal activity was reported in ethanol $(19 \mathrm{~mm})$ and ethyl acetate $(18.6 \mathrm{~mm})$, followed by $A$. niger $(18.3 \mathrm{~mm}, 15.1 \mathrm{~mm}), F$. oxysporum $(17.1 \mathrm{~mm}, 16.5 \mathrm{~mm})$. The active principle is gymnemic acid also possesses antimicrobial and sweet suppressing activities. Chloroform $(12 \mathrm{~mm})$ and petroleum ether $(11.5 \mathrm{~mm})$ extract remained sensitive towards $F$. oxysporum possessing least inhibition.

Table 3: Antimicrobial activity of synthesized silver nanoparticle

\begin{tabular}{|c|c|c|c|c|c|}
\hline \multirow[t]{2}{*}{ Microorganism } & \multicolumn{5}{|c|}{ Plant samples used in the study zone of inhibition in mm Glycirrhiza glabra } \\
\hline & $100 \mu l$ & $200 \mu \mathrm{l}$ & $300 \mu \mathrm{l}$ & $400 \mu \mathrm{l}$ & Agno $_{3}$ solution $200 \mu \mathrm{l}$ \\
\hline Bacillus sp. & $20.6 \pm 0.1$ & $21 \pm 0$ & $22.6 \pm 0.1$ & $24.5 \pm 0$ & $20 \pm 0$ \\
\hline Escherichia coli & $18.5 \pm 0$ & $19.2 \pm 0.2$ & $20.2 \pm 0.2$ & $21.3 \pm 0.1$ & $19.1 \pm 0.2$ \\
\hline Mycobacterium mucilaginosus & $14 \pm 0$ & $15.5 \pm 0$ & $16.4 \pm 0.3$ & $17 \pm 0$ & $14.5 \pm 0$ \\
\hline Klebsiella terrigena & $16.3 \pm 0.2$ & $17 \pm 0$ & $17.5 \pm 0$ & $18.7 \pm 0.2$ & $16.5 \pm 0$ \\
\hline Pseudomonas aeruoginosa & $17.6 \pm 0.1$ & $18.2 \pm 0$ & $19.6 \pm 0.2$ & $20.5 \pm 0$ & $17.3 \pm 0.3$ \\
\hline Shigella & $16.5 \pm 0$ & $17.7 \pm 0.1$ & $18 \pm 0$ & $19.4 \pm 0.2$ & $16 \pm 0$ \\
\hline Staphylococcus epidermis & $19 \pm 0$ & $20.6 \pm 0.1$ & $21.5 \pm 0$ & $22.3 \pm 0.3$ & $19.1 \pm 0.2$ \\
\hline Fusarium oxysporum & $14 \pm 0$ & $17.3 \pm 0.3$ & $18.5 \pm 0$ & $19.6 \pm 0.1$ & $13.5 \pm 0$ \\
\hline Penicillium & $17.6 \pm 0.1$ & $18 \pm 0$ & $19.1 \pm 0.2$ & $21.5 \pm 0$ & $17 \pm 0$ \\
\hline Aspergillus niger & $16.5 \pm 0$ & $17.5 \pm 0$ & $19 \pm 0$ & $21 \pm 0$ & $16.3 \pm 0.2$ \\
\hline
\end{tabular}

\footnotetext{
*values are mean of $\pm \mathrm{SD}, \mathrm{n}=3$
} 


\section{Microbicidal assay of synthesized AgNPs using G. sylvestrae}

Microbicidal efficacy of phytosynthesized AgNPs using G. sylvestrae were represented in table 3. Among various metal nanoparticles, silver nanoparticles (AgNPs) in particular have been the focus of increasing interest due to their peculiar properties which can be tailored for a specific application by controlling the shape, size and morphology of the nanoparticles $[48,49,50,51,52,53] .400 \mu \mathrm{l}$ of AgNPs remained resistant against Bacillus sp. $(24.5 \mathrm{~mm}), S$. epidermis $(22.3 \mathrm{~mm})$ and E. coli $(21.3 \mathrm{~mm})$ followed by $300 \mu \mathrm{l}$ of AgNPs $(22.6 \mathrm{~mm}, 21.5 \mathrm{~mm}, 20.2 \mathrm{~mm})$ possessing higher inhibition. Abutilon indicum synthesized nanoparticles in previous results revealed that high antimicrobial activities against $S$. typhi, E. coli, $S$. aureus and $B$. subtilis microorganisms [54]. The effective antimicrobial activity is due to a spherical shape and small size of AgNPs. Bacillus sp. $(21 \mathrm{~mm})$, S. epidermis $(20.6 \mathrm{~mm})$ and E. coli $(19.2 \mathrm{~mm})$ possess moderate zone of inhibition in $200 \mu \mathrm{l}$ of AgNPs. The irregular release of insufficient concentrations of silver ions from $\mathrm{AgNO}_{3}$ may be the reason for its restricted efficacy as antimicrobial agents, which can be enhanced using AgNPs because their large surface area makes them highly reactive [55]. Nps increases the contact area between AgNPs and microbe which in turn increases the inhibitory activity. The strain susceptible to $\mathrm{Al}_{2} \mathrm{O}_{3}$ nanoparticles exhibited a superior zone of inhibition (E. coli), whereas resistant strains exhibit a smaller zone of inhibition (Proteus vulgaris) [56]. Minimum inhibitory effect was observed in $100 \mu \mathrm{l}$ against M. mucilaginosus (14 mm). Tamboli and Lee (2013) demonstrated that the antimicrobial effect of SNPs was due to the breakage of double-stranded DNA molecules present in the bacteria [57]. One such size-dependent property has led to the development of dressing materials incorporated with nano-sized silver to enhance the wound healing property of the dressing materials [58].

Fungicidal activity of photosynthesis AgNPs indicate that maximum inhibition was observed in $400 \mu \mathrm{l}$ of AgNPs against Penicillium $(21.5 \mathrm{~mm})$, A. niger $(21 \mathrm{~mm})$ and F. oxysporum $(19.6 \mathrm{~mm})$. In addition, nanoparticles possess extremely large surface area that provides better contact and interaction with bacterial cells [59]. The biosynthesized AgNPs have been applied widely to prevent biomedical devices associated infections, food preservation, water purification, clothing, cosmetics, and other numerous pharmaceutical products $[60$, $61,62,63]$. Zone of inhibition was found to be moderate in $200 \mu \mathrm{l}$ of AgNPs (18.5 mm, $17.5 \mathrm{~mm}, 17.3 \mathrm{~mm})$. Minimum inhibitory effect was observed in $100 \mu$ l against Penicillium $(17.6 \mathrm{~mm})$, A. niger $(16.5 \mathrm{~mm})$ and $F$. oxysporum $(14 \mathrm{~mm})$. In this perspective nanoscale materials have emerged up as novel antimicrobial agents due to its unique chemical and physical properties [64]. The effective antimicrobial activity of the biosynthesized AgNPs in this study provides the capability of AgNPs as potential topical ointments for various infections without any side effects. This environmentally friendly approach is more biocompatible and cost-efficient and includes the capability of supporting larger synthesis $[65,66]$.

\section{CONCLUSION}

Naturally, plants have a broad array of phyto-biomolecules which act as reducing as well as stabilizing agents, characteristically responsible for increasing the biomedical applications of nanoparticles synthesized by green based principle. Secondary metabolites present in plants play an important role in synthesis. AgNPs inhibited the bacterial and fungal growth corroborating their biological properties.

\section{ACKNOWLEDGMENT}

The authors would like to extend their sincere gratitude to St. Josephs College, Trichy and Avinashiligam University, Coimbatore for the analytical facilities provided.

\section{AUTHORS CONTRIBUTIONS}

All the author have contributed equally.

\section{CONFLICT OF INTERESTS}

The authors declare that there is no conflict of interest.

\section{REFERENCES}

1. Nel AE, Madler L, Velegol D, Xia T, Hoek EMV, Somasundaran P, et al. Understanding biophysicochemical interactions at the nano-bio interface. Nat Mater 2009;8:543-57.
2. Sharma NC, Sahi SV, Nath S, Parsons JG, Gardea Torresde JL, Pal T. Synthesis of plant-mediated gold nanoparticles and catalytic role of biomatrix-embedded nanomaterials. Environ Sci Technol 2007;41:5137-42.

3. Hamed M, Givianrad M, Moradi A. Biosynthesis of silver nanoparticles using the marine sponge. Orient J Chem 2015;31:1961-7.

4. Kumari A, Yadav SK, Yadav SC. Biodegradable polymeric nanoparticles based drug delivery systems. Colloids Surf B Biointerfaces 2010;75:1-18.

5. Rauwel P, Kunal S, Ferdov S, Rauwel E. A review on the green synthesis of silver nanoparticles and their morphologies studied via TEM. Adv Mater Sci Eng 2015;9:682749.

6. Kumar B, Smita K, Cumbal L, Debut A. Synthesis of silver nanoparticles using Sacha inchi (Plukenetia volubilis L.) leaf extracts. Saudi J Biol Sci 2014b;21:605-9.

7. Mehmood A, Murtaza G, Bhatti TM, Raffi M, Kausar R. Antibacterial efficacy of silver nanoparticles synthesized by a green method using bark extract of Melia azedarach L. J Pharm Innovare 2014;9:238-45.

8. Kumar B, Angulo Y, Smita K, Cumbal L, Debut A. Capuli cherrymediated green synthesis of silver nanoparticles under white solar and blue LED light. Particuology 2016;24:123-8.

9. Kumar B, Smita K, Cumbal L, Angulo Y. Fabrication of silver nanoplates using Nephelium lappaceum (Rambutan) peel: a sustainable approach. J Mol Liq 2015b;211:476-80.

10. Kumar B, Smita K, Cumbal L, Debut A. Sacha inchi (Plukenetia volubilis L.) oil for one-pot synthesis of silver nanocatalyst: an ecofriendly approach. Ind Crops Prod 2014c;58:238-43.

11. Shameli K, Ahmad MB, Zamanian A, Sangpour P, Shabanzadeh P, Abdollahi Y, et al. Green biosynthesis of silver nanoparticles using Curcuma longa tuber powder. Int J Nanomed 2012;7:5603-10.

12. Rajeshkumar S. Anticancer activity of eco-friendly gold nanoparticles against lung and liver cancer cells. J Genet Eng Biotechnol 2016;14:195-202.

13. Khan M, Khan ST, Khan M, Adil SF, Musarrat J, Al-Khedhairy AA, et al. Antibacterial properties of silver nanoparticles synthesized using Pulicaria glutinosa plant extract as a green bioreduction. Int J Nanomed 2014;9:3551-65.

14. Kumar PPN, Pammi SVN, Kollu P, Satyanarayana KVV, Shameem U. Green synthesis and characterization of silver nanoparticles using Boerhavia diffusa plant extract and their antibacterial activity. Ind Crops Prod 2014;52:562-6.

15. Jeyaraj M, Sathishkumar G, Sivanandhan G, Mubarak Ali D, Rajesh M, Arun R, et al. Biogenic silver nanoparticles for cancer treatment: an experimental report. Colloids Surf B Biointerfaces 2013;106:86-92.

16. Balavigneswaran CK, Sujin Jeba Kumar T, Moses Packiaraj R, Prakash S. Rapid detection of $\mathrm{Cr}(\mathrm{VI})$ by AgNPs probe produced by Anacardium occidentale fresh leaf extracts. Appl Nanosci 2014;4:367-78.

17. Kumar P, Govindarajua M, Senthamilselvi S, Premkumar K. Photocatalytic degradation of methyl orange dye using silver (Ag) nanoparticles synthesised from Ulva lactuca. Colloids Surf B Biointerfaces 2013;103:658-61.

18. Mohapatra B, Kuriakose S, Mohapatra S. Rapid green synthesis of silver nanoparticles and nanorods using Piper nigrum extract. J Alloys Comp 2015;637:119-26.

19. Karadeniz F, Burdurulu HS, Koca N, Soyer Y. Antioxidant activity of selected fruits and vegetables grown in Turkey. Turk J Agric Forest 2005;29:297-303.

20. Kokate CK, Purohit AP, Gokhale SB. Pharmacognosy. 36th ed. Pune: Nirali Prakashan; 2006. p. 252.

21. Kumaran A, Karunakaran JR. In vitro antioxidant activities of methanol extracts of five Phyllanthus species from India. LWTFood Sci Technol 2007;40:344-52.

22. Ali Ahmed $\mathrm{AB}$, Rao AS, Rao MV. In vitro production of gymnemic acid from Gymnema sylvestrae (Retz) R. Br. ex roemer and schultes through callus culture under abiotic stress conditions. Methods Mol Biol 2009;547:93-105.

23. Harborne JB. Phytochemical methods. A guide to modern techniques of plant analysis. 1st ed. Chapman and Hall Ltd.; 1973. p. 279.

24. Kumar V, Yadav SC, Yadav SK. Syzygium cumini leaf and seed extract mediated biosynthesis of silver nanoparticles and their characterization. J Chem Technol Biotechnol 2010;85:1301-9. 
25. NCCLS. Performance standards for antimicrobial susceptibility testing-wayne. 10th ed. NCCLS; 2010. p. M2-A8.

26. Cheesbrough M. District laboratory practice in tropical countries, part 2. Cambridge University Press: Cambridge, UK; 2000. p. 434.

27. Stuart BH. Polymer analysis. United Kingdom: John Wiley and Sons; 2002.

28. Chakrapani P, Venkatesh K, Chandra Sekhar SB, Arun JB, Prem K, Amareshwari P, et al. Phytochemical, pharmacological importance of Patchouli (Pogostemon cablin (Blanco) Benth) an aromatic medicinal plant. Int J Pharm Sci Rev Res 2013;21:7-15.

29. Priya K, Krishnakumari S. Phytochemical analysis of Achyranthes aspera and its activity on sesame oil induced lipid peroxidation. Anc Sci Life 2007;27:6-10.

30. Netala VR, Ghosh SB, Bobbu PL, Anitha D, Vijaya T. Triterpenoid saponins: a review on biosynthesis, applications and mechanism of their action. Int J Pharm Pharm Sci 2014;7:24-8.

31. Komes D, Belscak Cvitanovic A, Horzic D, Rusak G, Likic S, Berendika M. Phenolic composition and antioxidant properties of some traditionally used medicinal plants affected by the extraction time and hydrolysis. Phytochem Anal 2011;22:172-80.

32. Quideau S, Deffieux D, Douat Casassus C, Pouysegu L. Plant polyphenols: chemical properties, biological activities, and synthesis. Angew Chem Int Ed 2011;50:586-621.

33. Rice Evans CA, Miller NJ, Bolwell PG, Bramley PM, Pridham JB. The relative antioxidant activities of plant-derived polyphenolic flavonoids. Free Radical Res 1995;22:375-83.

34. Tavakoli F, Salavati Niasari M, Mohandes F. Green synthesis and characterization of graphene nanosheets. Mater Res Bull 2015;63:51-7.

35. Iravani S, Zolfaghari B. Green synthesis of silver nanoparticles using Pinus eldarica bark extract. BioMed Res Int 2013:639725. http://dx.doi.org/10.1155/2013/639725

36. Suna Q, Cai X, Li J, Zheng M, Chenb Z, Yu CP. Green synthesis of silver nanoparticles using tea leaf extract and evaluation of their stability and antibacterial activity. Colloid Surf A Physicochem Eng Asp 2014;444:226-31.

37. Dinesh S, Karthikeyan S, Arumugam P. Biosynthesis of silver nanoparticles from Glycyrrhiza glabra root extract. Arch Appl Sci Res 2012;4:178-87.

38. Sable N, Gaikwad S, Bonde S, Gade A, Rai M. Phytofabrication of silver nanoparticles by using aquatic plant Hydrila Verticilata. Nus Biosci 2012;4:45-9.

39. Sadeghi B, Gholamhoseinpoor F. A study on the stability and green synthesis of silver nanoparticles using Ziziphora tenuior (Zt) extract at room temperature. Spectrochim Acta Part A Mol Biomol Spectrosc 2015;134:310-5.

40. Firdhouse MJ, Lalitha P, Sripathi SK. Novel synthesis of silver nanoparticles using leaf ethanol extract of Pisonia grandis (R. Br). Der Pharm Chem 2012;4:2320-6.

41. Awwad AM, Salem NM, Abdeen AO. Biosynthesis of silver nanoparticles using Loquat leaf extract and its antibacterial activity. Adv Mater Lett 2013;4:338-42.

42. Veshara M, Izel B, Suresh BNK, Joyce NM. Enhancing antidiabetic and antimicrobial performance of Ocimum basilicum and Ocimum sanctum (L.) using silver nanoparticles. Saudi J Biol Sci 2017;24:1294-305.

43. Raju VSR, Kannababu S, Subba Raju G. Standardization of Gymnema sylvestrae R. Br. by high-performance thin layer chromatography-an improved method. Phytochem Anal 2006;17:192-6.

44. Perez C, Pauli M, Bazerque P. An antibiotic assay by the agarwell diffusion method. Acta Biol Med Exp 1990;15:113-5.

45. Ghosh A, Das BK, Roy A, Mandal B, Chanda G. Antibacterial activity of some medicinal plant extracts. J Nat Med 2008;62:259-62.

46. Paz EA, Cerdeiras MP, Fernandez J, Ferreira F, Moya P, Soubes $\mathrm{M}$, et al. screening of uruguayan medicinal plants for antimicrobial activity. J Ethnopharmacol 1995;45:67-70.

47. Segarajah A, Gunasingam M, Kalamathy M. Antibacterial activity of leaf extracts of Gymnema sylvestrae (R. Br.). Med Plants Int J Phytomed Related Ind 2011;3:139-43.
48. Vidhu VK, Philip D. Spectroscopic, microscopic and catalytic properties of silver nanoparticles synthesized using Saraca indica flower. Spectrochim Acta Part A Mol Biomol Spectrosc 2014;117:102-8.

49. Ganaie SU, Tasneem A, Anuradha J, Abbasi SA. Biomimetic synthesis of silver nanoparticles using the amphibious weed ipomoea and their application in pollution control. J King Saud Univ Sci 2014;26:222-9.

50. Ghosh S, Patil S, Ahire M, Kitture R, Kale S, Pardesi K, et al. Synthesis of silver nanoparticles using Dioscorea bulbifera tuber extract and evaluation of its synergistic potential in combination with antimicrobial agents. Int J Nanomed 2012;7:483-96.

51. El Sheekh MM, El Kassas HY. Algal production of nanosilver and gold: their antimicrobial and cytotoxic activities: a review. J Genet Eng Biotechnol 2016;14:299-310.

52. Chinnappan S, Kandasamy S, Muthusamy G, Balakrishnan S, Arumugam S, Murugesan S, et al. Acorus calamus rhizome extract mediated biosynthesis of silver nanoparticles and their bactericidal activity against human pathogens. J Genet Eng Biotechnol 2015;13:93-9.

53. Mohammad MA, Abbas Y, Mehdi HM, Somayeh B. Effects of antimicrobial activity of silver nanoparticles on invitro establishment of $\mathrm{G} \times \mathrm{N} 15$ (hybrid of almond $\times$ peach) rootstock. J Genet Eng Biotechnol 2014;12:103-10.

54. Ashok kumar S, Ravi S, Kathiravan V, Velmurugan S. Synthesis of silver nanoparticles using $A$. indicum leaf extract and their antibacterial activity. Spectrochim Acta Part A Mol Biomol Spectrosc 2015;134:34-9.

55. Gopal S, Poosali HG, Dhanasegaran K, Durai P, Devadoss D, Nagaiya R, et al. Green synthesis of silver nanoparticles using Delphinium denudatum root extract exhibits antibacterial and mosquito larvicidal activities. Spectrochim Acta Part A Mol Biomol Spectrosc 2014;127:61-6.

56. Geoprincy G, Gandhi NN, Renganathan S. Novel antibacterial effects of alumina nanoparticles on Bacillus cereus and Bacillus subtilis in comparison with antibiotics. Int J Pharm Pharm Sci 2012;4:544-8.

57. Zamani M, Prabhakaran MP, Ramakrishna S. Advances in drug delivery via electrospun and electrosprayed nanomaterials. Int J Nanomed 2013;8:2997-3017.

58. Tamboli DP, Lee DS. Mechanistic antimicrobial approach of extracellularly synthesised silver nanoparticles against gram positive and gram-negative bacteria. J Hazard Mater 2013;260:878-84

59. Muthuraman P, Doo HK. ZnO nanoparticles augment ALT, AST ALP and LDH expressions in C2C12 cells. Saudi J Biol Sci 2015;2:679-84

60. Gangadharan D, Harshvardan K, Gnanasekar G, Dixit D, Popat KM, Anand PS. Polymeric microspheres containing silver nanoparticles as a bactericidal agent for water disinfection. Water Res 2010;44:5481-7.

61. Kokura S, Handa O, Takagi T, Ishikawa T, Naito Y, Yoshikawa T. Silver nanoparticles as a safe preservative for use in cosmetics. Nanomed Nanotechnol Biol Med 2010;6:570-4.

62. Tian J, Wong KK, Ho CM, Lok CN, Yu WY, Che CM, et al. Topical delivery of silver nanoparticles promotes wound healing. Chem Med Chem 2007;2:129-36.

63. Dastjerdi R, Montazer M. A review on the application of inorganic nanostructured materials in the modification of textiles: focus on anti-microbial properties. Colloids Surf B 2010;79:5-18.

64. Ravi Chandrika K, Kiranmayi P, Ravikumar RVSSN. Role of zinc oxide nanoparticles enhancing the antibacterial activity of antibiotics. Asian J Pharm Clin Res 2012;4:97-9.

65. Arunachalam KD, Annamalai SK, Hari S. One-step green synthesis and characterization of leaf extract-mediated biocompatible silver and gold nanoparticles from Memecylon umbellatum. Int J Nanomed 2013;8:307-15.

66. Mittal AK, Tripathy D, Choudhary A, Aili PK, Chatterjee A, Singh IP, et al. Bio-synthesis of silver nanoparticles using Potentilla fulgens wall. ex-hook. and its therapeutic evaluation as an anticancer and antimicrobial agent. Mater Sci Eng C Mater Biol Appl 2015;53:120-7. 